\title{
REGULATION OF TRANSCRIPTION OF CORONAVIRUSES
}

\author{
Guido van Marle, Robbert G. van der Most, Tahar van der Straaten, \\ Willem Luytjes, and Willy J.M. Spaan \\ Department of Virology \\ Faculty of Medicine \\ Leiden University \\ PO Box 320 \\ 2300 AH Leiden, The Netherlands
}

\begin{abstract}
To study factors involved in regulation of transcription of coronaviruses, we constructed defective interfering (DI) RNAs containing sg RNA promoters at multiple positions. Analysis of the amounts of sg DI RNA produced by these DIs resulted in the following observations: (i) a downstream promoter downregulates an upstream promoter; (ii) an upstream promoter has little or no effect on the activity of a downstream promoter. Our data suggest that attenuation of upstream promoter activities by downstream promoter sequences plays an important role in regulating the amounts of sg RNAs produced by coronaviruses. Our observations are in accordance with the models proposed by Konings et al. (8) and Sawicki and Sawicki (16).

Coronaviruses produce a $3^{\prime}$-coterminal nested set of subgenomic ( $\mathrm{sg}$ ) mRNAs. All sg mRNAs contain a common leader sequence derived from the $5^{\prime}$ end of the genome. For mouse hepatitis virus MHV this leader sequence is 72 nucleotides (nt) in length (20). The joining of the $5^{\prime}$ leader RNA to the mRNA is believed to be a discontinuous transcription process $(10,19)$, since the results of UV transcription mapping argue against RNA splicing $(5,23)$. On the genome the transcription units for the mRNAs are preceded by the intergenic sequence (IS) $(10,19)$. For MHV every IS contains a sequence element related to the consensus $5^{\prime}$ AAUCUAAAC 3' $(2,8,18)$. These IS elements function, on the negative stranded RNA template, as promoters for sg mRNA synthesis $(14,22)$. On the negative strand the IS promoter elements are called intergenic promoter sequence (IPS).

The mechanism of coronavirus sg mRNA synthesis is a subject of considerable debate. In earlier experiments only genome length negative strands were found (11) and it was believed that genomic negative strands were the exclusive templates for the synthesis of $s g$ mRNAs. To explain the synthesis of leader containing sg mRNAs, it has been proposed that short leader RNA species act as primers $(9,20)$. According to this leader-primed
\end{abstract}


transcription model, the leader RNAs are transcribed from the $3^{\prime}$ end of the genome, translocated to the several IPSs on the negative stranded template and then extended to form leader containing sg RNAs. The key observation that supports the priming of the leader during transcription initiation is the fact that the leader RNA includes an IS that allows base pairing between the $3^{\prime}$ end of the leader and the IPS (2).

The discovery in recent years of sg negative strands $(4,6,16,17)$ has had consequences for the leader primed transcription model. The sg negative strands seem to be involved actively in the synthesis of sg mRNAs $(3,16)$, although it has been argued that they are merely dead-end products synthesized from the sg mRNAs (6). Additional models have now been proposed for coronavirus transcription, in which the sg mRNAs are transcribed from $\mathrm{sg}$ negative stranded templates.

Sethna et al. (17) speculated that sg mRNAs produced in the classic leader-primed fashion, are amplified from negative stranded counterparts as replicons. However, to date all attempts to obtain direct evidence for mRNA replication have failed. Transfecting synthetic mRNAs into coronavirus infected cells did not result in replication of the sg RNA $(1,12,14)$. However, it could well be that transfected sg RNAs are not suitable templates for replication.

Sawicki and Sawicki (16) proposed an alternative model. They suggested that sg negative strands are synthesized first to serve as templates for the synthesis of the corresponding mRNA and not vice versa. In this model transcription should be regulated on the level of negative strand synthesis.

Many of the basic features of coronavirus transcription are unclear because of the lack of an appropriate experimental system. Recently, it has been shown that full length cDNA clones of defective interfering (DI) RNAs can be used to study MHV mRNA transcription (7,13-16,22). Inserting an IS into the genome of a synthetic MHV DI-RNA and transfecting this DI-RNA into MHV infected cells gives rise to a DI derived sg RNA. To study transcription, we use a DI RNA vector based on a full length cDNA clone of a natural occuring 5.5 kb DI RNA of MHV-A59, pMIDIC $(21,22)$.

Coronavirus mRNAs are, in general, synthesized in amounts that are inversely related to their size. Previously, we have proposed that the generation of this gradient of sg mRNA arizes because larger RNA molecules are more prone to premature transcription termination and therefore produced less abundantly than smaller RNAs (8). There are two stages in which transcription termination can occur. In one case transcription initiation events on downstream promoters on the negative strands are attenuating factors for positive strand synthesis (8). Alternatively, premature termination could occur during negative strand synthesis (16). This is based on the model in which a nested set of sg negative strands is synthesized first. In this case larger negative strands are produced in lower quantities because they encounter more transcription attenuating antipromoters on the positive strand during their synthesis then smaller ones.

To test the hypothesis of attenuation we inserted wildtype (wt) as well as mutant sg RNA3 promoters at different positions of our DI-RNA vector (Fig. 1). The mutant RNA3 promoter is inactive due to a single point mutation. DI-RNAs containing the wt and the mutant promoters replicated efficiently and produced sg DI-RNAs of the expected length. The DI-RNA constructs containing a wt RNA3 promoter at position A or C (Fig. 1), produced equal amounts of sg DI-RNA. However, analysis of the sg RNA synthesis of the DI-RNA containing wt promoters at positions $\mathrm{A}$ and $\mathrm{C}$ showed a difference in promoter activities. The activity of the promoter at position A was reduced by the presence of the wt promoter at position $\mathrm{C}$, while the activity of the promoter at position $\mathrm{C}$ remained the same. The presence of an additional wt promoter at position B, downstream of A (Fig. 1), reduced the activity of the wt promoter at position A to an almost undetectable level. The activity of the promoter at position $\mathrm{C}$ was not affected by the presence of an additional upstream promoter. 


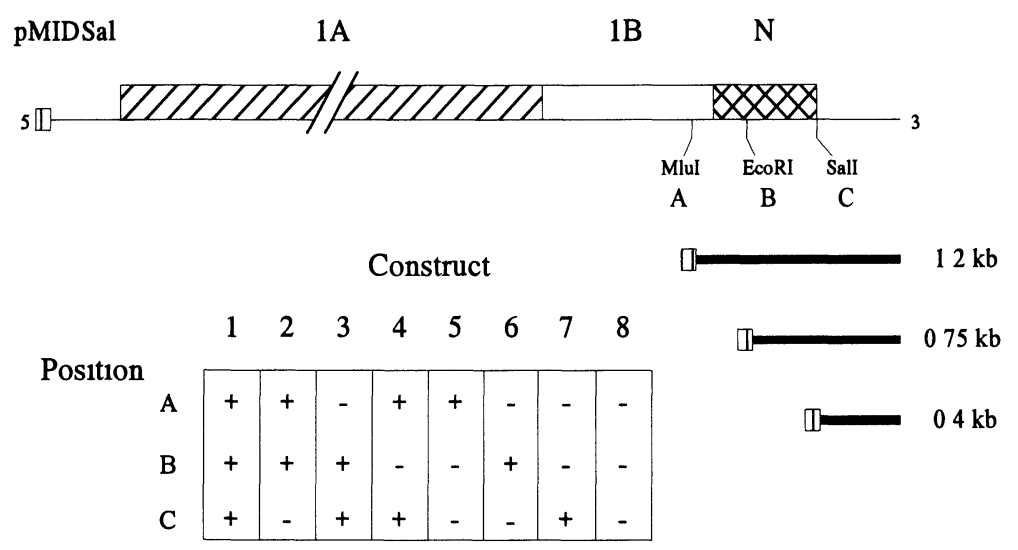

Figure 1. Schematic representation of the constructs contanning RNA3 promoters the MluI, EcoRI and SalI site of pMIDSal (postitions A, B and C on the DI RNA) The black bars represent the subgenomic DI RNAs produced by the DIs The table shows which constructs contain which combinations of wildtype and mutant RNA3 promoters $(+=$ wildtype (UAAUCUAAAC), - = mutant (UAAUGUAAAC))

From these data we concluded that a downstream promoter attenuates the amounts of sg RNA generated by upstream promoter and not vice versa Our observations are in agreement with the models of Konıngs et al (8) and Sawick1 and Sawick1 (16) However, our data can not discriminate between attenuation durıng positive or negative strand synthesis We also observed that a wt RNA3 promoter at position B gave rise to more sg DI-RNA then at positions $A$ and $C$ Even in the presence of wt promoters at positions A and C, the sg DI-RNA produced by the promoter at position $\mathrm{B}$ is the most abundant This suggests that there are additional factors that regulate the accumulation of sg RNAs It could be possible that the polymerase initiates or terminates (depending on the model one prefers) transcription more efficiently at the promoter at position B Protein binding domains or the RNA secondary structure could play a role in this preference for the promoter at position $B$ This could explain why for the coronaviruses TGEV and FIPV the smallest sg mRNA is not the most abundant as the gradient would predict Nevertheless, our data suggest that attenuation of promoter activities by promoter sequences is important in regulating the amounts of sg mRNAs of coronaviruses

\section{REFERENCES}

1 Brian, D A, R -Y Chang, M A Hofmann, and P B Sethna 1994 Role of subgenomic minus-strand RNA in coronavirus replication Arch Virol 9 173-180

2 Budzılowicz, C J, S P Wilczynski, and S R Weiss 1985 Three intergenic regions of coronavirus mouse hepatitıs virus strain A59 genome RNA contain a common nucleotıde sequence that is homologous to the 3 ' end of the viral mRNA leader sequence $J$ Virol 53 834-840

3 Hofmann, M A, R -Y Chang, S Ku, and D A Brian 1993 Leader-mRNA junction sequences are unique for each subgenomic mRNA species in the bovine coronavirus and remain so throughout persistent infection Virology 196163171

4 Hofmann, M A, P B Sethna, and D A Brian 1990 Bovine coronavirus mRNA replication contınues throughout persistent infection in cell culture $J$ Virol 64 4108-4114

5 Jacobs, L, W J M Spaan, M C Horzinek, and B A M van der Zeijst 1981 Synthesıs of subgenomic mRNAs of mouse hepatitıs virus is initiated independently Evidence from UV transcription mapping $J$ Virol 39 401-406 
6 Jeong, YS and S Makıno 1992 Mechanısm of coronavirus transcription duration of primary transcription initiation activity and effects of subgenomic RNA transcription on RNA replication $J$ Virol $663339-3346$

7 Joo, M and S Makıno 1992 Mutagenic analysıs of the coronavirus intergenic consensus sequence J Virol 66 6330-6337

8 Konıngs, D A M, P J Bredenbeek, J F H Noten, P Hogeweg, and W J M Spaan 1988 Differential premature termination of transcription as a proposed mechanism for the regulation of coronavirus gene expression Nucl Acids Res 16 10849-10860

9 La1, M M, R S Baric, P R Brayton, and S A Stohlman 1984 Characterization of leader RNA sequences on the virion and mRNAs of mouse hepatitıs virus, a cytoplasmic RNA virus Proc Natl Acad Sc1 USA 81 3626-3630

10 La1, M M C 1990 Coronavirus - organization, replication and expression of genome Ann Rev Microbiol 44 303-333

11 Lal, M M C , C D Patton, and S A Stohlman 1982 Replıcation of mouse hepatitıs virus negatıvestranded RNA and replicative form RNA are of genome length J Virol 44 487-492

12 Luytjes, W, H Gerritsma, and W J M Spaan 1994 Unpublished results

13 Makıno, S and M Joo 1993 Effect of intergenic consensus sequence flankıng sequences on coronavirus transcription J Virol 67 3304-3311

14 Makıno, S, M Joo, and J K Makıno 1991 A system for study of coronavırus mRNA synthesıs a regulated, expressed subgenomic defective interferıng RNA results from intergenic site insertion $\mathrm{J}$ Virol $656031-6041$

15 Makıno, S, K Yokomorı, and M M La1 1990 Analysis of efficiently packaged defective interfering RNAs of murıne coronavirus localızation of a possible RNA-packaging signal J Virol 64 6045-6053

16 Sawickı, S G and D L Sawickı 1990 Coronavirus transcription subgenomic mouse hepatitıs virus replicative intermediates function in RNA synthesis J Virol 64 1050-1056

17 Sethna, PB, S L Hung, and D A Brian 1989 Coronavirus subgenomic minus-strand RNAs and the potential for mRNA replicons Proc Natl Acad Scı USA 86 5626-5630

18 Shieh, C-K, H J Lee, K Yokomorı, N La Monıca, S Makıno, and M M C La1 1989 Identification of a new transcriptional initiation site and the corresponding functional gene $2 \mathrm{~b}$ in the murine coronavirus RNA genome J Virol 63 3729-3736@RefNum=19

Spaan, W, D Cavanagh, and M C Horzınek 1988 Coronaviruses Structure and genome expression J Gen Virol 69 2939-2952

20 Spaan, W, H Delius, M Skınner, J Armstrong, P Rottier, S Smeekens, B A M van der Zeijst, and S G Siddel 1983 Coronavirus mRNA synthesis involves fusion of non-contiguous sequences EMBO J 2 1839-1844

21 Van der Most, R G, P J Bredenbeek, and W J M Spaan 1991 A domain at the 3' end of the polymerase gene is essential for the encapsidation of coronavirus Defectıve Interfering RNAs J Virol 65 3219-3226

22 Van der Most, R G, R J de Groot, and W J M Spaan 1994 Subgenomic RNA synthesis directed by a synthetic defective interfering RNA of mouse hepatitıs virus a study of coronavirus transcription initiation J Virol 68 3656-3666

23 Yokomorı, K, L R Banner, and M M La1 1992 Coronavirus mRNA transcription UV light transcriptıonal mapping studies suggest an early requirement for a genomic length template J Virol 664671 4678 